\title{
Portuguese validation of the Symptom Inventory of the M.D. Anderson Cancer Center*
}

\author{
VALIDAÇÃO DO INVENTÁRIO DE SINTOMAS DO M.D. ANDERSON CANCER CENTER \\ PARA A LÍNGUA PORTUGUESA
}

\section{VALIDACIÓN DEL INVENTARIO DE SÍNTOMAS DEL M.D. ANDERSON CANCER CENTER PARA LA LENGUA PORTUGUESA}

\author{
Adriane Cristina Bernat Kolankiewicz', Edvane Birelo Lopes De Domenico², Luís Felipe \\ Dias Lopes ${ }^{3}$, Tânia Solange Bosi de Souza Magnago ${ }^{4}$
}

\begin{abstract}
Objective: To analyze the reliability and validity of the psychometric properties of the Brazilian version of the instrument for symptom assessment, titled MD Anderson Symptom Inventory - core. Method: A cross-sectional study with 268 cancer patients in outpatient treatment, in the municipality of ljuí, state of Rio Grande do Sul, Brazil. Results: The Cronbach's alpha for the MDASI general, symptoms and interferences was respectively (0.857), (0.784) and (0.794). The factor analysis showed adequacy of the data (0.792). In total, were identified four factors of the principal components related to the symptoms. Factor I: sleep problems, distress (upset), difficulties in remembering things and sadness. Factor II: dizziness, nausea, lack of appetite and vomiting. Factor III: drowsiness, dry mouth, numbness and tingling. Factor IV: pain, fatigue and shortness of breath. A single factor was revealed in the component of interferences with life $(0.780)$, with prevalence of activity in general (59.7\%), work (54.9\%) and walking (49.3\%). Conclusion: The Brazilian version of the MD Anderson Symptom Inventory - core showed adequate psychometric properties in the studied population.
\end{abstract}

\section{DESCRIPTORS}

Neoplasms

Signs and symptoms

Symptoms assessment

Validation studies

Oncology nursing

\begin{abstract}
RESUMO
Objetivo: Analisar a confiabilidade e a validade das propriedades psicométricas da versão brasileira do instrumento de avaliação de sintomas, intitulado Inventário de Sintomas do M.D. Anderson - core. Método: Estudo transversal do qual participaram 268 pacientes com câncer em tratamento ambulatorial, do Município de ljuí, Rio Grande do Sul, Brasil. Resultados: 0 Alfa de Cronbach MDASI geral, os sintomas e as interferências foram respectivamente $(0,857),(0,784)$ e $(0,794)$. A análise fatorial demonstrou adequação dos dados $(0,792)$. Identificaram-se quatro fatores dos principais componentes relacionados aos sintomas. Fator I: problemas de sono, preocupações, dificuldades de lembrar-se das coisas e tristeza. Fator II: enjoo, náuseas, falta de apetite e vômito. Fator III: sonolência, boca seca, dormência e formigamento. Fator IV: dor, fadiga e falta de ar. Evidenciou-se um único fator no componente interferências na vida $(0,780)$, prevalecendo para atividade em geral $(59,7 \%)$, trabalho $(54,9 \%)$ e para caminhar (49,3\%). Conclusão: A versão brasileira do Inventário de M.D. Andersoncore mostrou propriedades psicométricas adequadas na população avaliada.
\end{abstract}

\author{
DESCRITORES \\ Neoplasias \\ Sinais e sintomas \\ Avaliação de sintomas \\ Estudos de validação \\ Enfermagem oncológica
}

\section{RESUMEN}

Objetivo: Analizar la confiabilidad y la validad de las propiedades psicométricas de la versión brasileña del instrumento de evaluación de síntomas, titulado Inventario de Síntomas del M.D. Anderson - core. Método: Estudio transversal del que participaron 268 pacientes con cáncer en tratamiento ambulatorio, del Municipio de ljuí, Rio Grande do Sul, Brasil. Resultados: El Alfa de Cronbach MDASI general, los síntomas y las interferencias fueron respectivamente $(0,857),(0,784)$ y $(0,794)$. El análisis factorial demostró la adecuación de los datos $(0,792)$. Se identificaron cuatro factores de los principales componentes relacionados con los síntomas. Factor I: problemas de sueño, preocupaciones, dificultades de recordar las cosas y tristeza. Factor II: mareo, náuseas, falta de apetito y vómito. Factor III: somnolencia, boca seca, adormecimiento y hormigueo. Factor IV: dolor, fatiga y falta de aliento. Se evidenció un solo factor en el componente interferencias en la vida $(0,780)$, prevaleciendo para la actividad en general $(59,7 \%)$, trabajo $(54,9 \%)$ y para caminar $(49,3 \%)$. Conclusión: La versión brasileña del Inventario de M.D. Anderson-core mostró propiedades psicométricas adecuadas en la población evaluada.

\section{DESCRIPTORES \\ Neoplasias \\ Signos y síntomas \\ Evaluación de síntomas \\ Estudios de validación \\ Enfermería oncológica.}

\footnotetext{
*Extracted from the thesis "Relations among clinical symptoms, social support and the interference in the daily lives of cancer patients", Post-graduate Program, Escola Paulista de Enfermagem, Universidade Federal de São Paulo, 2013. 1 Professor, PhD, Department of Life Sciences, Universidade do Noroeste do Estado do Rio Grande do Sul, ljuí, RS, Brazil. ${ }^{2}$ Adjunct Professor, Department of Clinical and Surgical Nursing, Escola Paulista de Enfermagem, Universidade Federal de São Paulo, São Paulo, SP, Brazil. ${ }^{3}$ Associate Professor, Universidade Federal de Santa Maria, Santa Maria, RS, Brazil. ${ }^{4}$ Adjunct Professor, Department of Nursing, Center for Health Sciences, Universidade Federal de Santa Maria, Santa Maria, RS, Brazil.
} 


\section{INTRODUCTION}

Cancer is a group of diseases that invariably causes many signs and symptoms on patients. It should be diagnosed and treated early by the therapeutic modalities to improve the clinical condition of patients, ensuring the possibility of therapeutic interventions against cancer and especially, of regaining quality of life with the control and/or eradication of the disease ${ }^{(1)}$. The cancer treatment comprises surgery, radiation therapy (RT), chemotherapy (chemo), the hormone therapy and specific targeted therapies, which may be used alone or conjugated ${ }^{(2)}$.

Cancer is a disease of aggressive and progressive evolution that may jeopardize the lives of patients in physical, psychological or social aspects ${ }^{(3)}$. It has deleterious symptoms and prolonged treatment, associated with side effects of treatment and/or amputation/mutilation resulting from surgical procedures ${ }^{(4)}$. The symptoms are the result of a variety of conditions, whether socio-cultural, behavioral, psychological and physiological that occur individually or collectively ${ }^{(5)}$ and also correlate with the changes experienced in daily activities ${ }^{(6)}$.

The evaluation of symptoms is critical and allows identifying complications early, as well as minimizing or preventing possible changes in the functional capacity of patients. For that purpose, there are several instruments that measure individual or multiple symptoms. Among the instruments available in the literature, there is the MD Anderson Symptom Inventory - core (MDASI), an instrument that assesses the severity of symptoms and their daily impact in the last 24 hours. It was initially developed in English in the United States ${ }^{(7)}$.

The MDASI was linguistically and psychometrically validated in Japanese ${ }^{(8)}, \operatorname{Greek}^{(9)}$, Chinese ${ }^{(10)}$, Russian $^{(11)}$, Korean ${ }^{(12)}$, Thai(13), Filipino ${ }^{(14)}$, Arabic $^{(15)}$ and French ${ }^{(16)}$. However, in Brazil this instrument had only linguistic validation ${ }^{(5)}$, which demonstrated the need for its psychometric validation. Given the variability of symptoms presented by patients due to the illness and treatment, the assessment of multiple symptoms by the MDASI makes this instrument an important tool for clinical and research activities, justifying the intention of validating it for use in the Brazilian population.

From this context, this study aimed at assessing the reliability and validity of the psychometric properties of the Brazilian version of the MD Anderson Symptom Inventory-core (MDASI).

\section{METHOD}

This is a cross-sectional study carried out in the outpatient Oncology High Complexity Center (CACON) of the Hospital de Caridade de ljuí $(\mathrm{HCl})$, in the municipality of Ijuí, state of Rio Grande do Sul (RS), Brazil. The study population consisted of 790 patients undergoing cancer treatment, residents in ljuí/RS, who were registered in the CACON system.

The selection of participants was by convenience sampling, with data collection between July and December 2012. The inclusion criteria were the following: over eighteen years of age; patients with a diagnosis of cancer; residents of the city of ljuí; and undergoing cancer treatment for at least three months in a therapeutic modality that may be surgical, chemotherapy, hormone therapy, radiotherapy or combined. The patients excluded from the sample were the following: in the present condition of disease-free follow-up; with auto and allopsychic disorientation that prevented them from responding to the instruments; those who were not aware of their cancer diagnosis, attested by the doctor or family member.

Patients were invited to join the study from their appointments in the unit for consultation or the completion of treatment. The instrument was completed by those responsible for data collection, after the participants accepted to take part in the study and signed the Informed Consent Form (ICF) in a room to ensure their privacy.

According to the selection criteria, 471 patients (59.6\%) were excluded, a total eligible population of 319 patients (40.4\%). Among these, 268 (84\%) participated in the study. The losses $(n=51,16 \%)$ were due to death during collection ( $n=46,90.2 \%)$, three $(5.9 \%)$ did not attend the appointment (they were confined to bed at home) and two $(3.9 \%)$ refused to participate in the study. In order to check the statistical significance of the number of patients in the study, the following criteria were adopted: estimated proportion of 50\%, sampling error of $5 \%$ and a significance level of $5 \%$. From the sample size calculation, a minimum of 176 patients would be necessary.

The data collection was carried out by one of the authors, a doctorate student in the study period, and also by previously trained nursing academics. The instrument used had closed questions regarding demographic, economic and clinical characteristics (prepared by the researchers), and the Brazilian version of the MD Anderson Symptom Inventory (MDASI) - core $^{(5)}$.

The Epi-Info ${ }^{\circledR} 6.04$ software was used for organization of data that were independently double entered. After corrections of errors and inconsistencies, the statistical analysis was done using the Statistical Package for the Social Sciences (SPSS) version 18.0 for windows.

The categorical variables were expressed as absolute frequencies and proportions. The quantitative variables were described by measures of central tendency (mean or median) and dispersion (standard deviation or interquartile range) according to the distribution of normality assessed by the Kolmogorov-Smirnov test. The intensity of the cancer symptoms (component 1 ) and their interference in the daily lives of these patients (component 2) 
was assessed by the Brazilian version of MDASI after the authorization for using the instrument given by the MD Anderson Cancer Center, University of Texas, USA.

The component 1, intensity of symptoms in the last 24 hours, has 13 items (pain, fatigue, dizziness and nausea, sleep problems, distress (upset), dyspnea, difficulty in remembering things, lack of appetite, drowsiness, dry mouth, sadness, vomiting, numbness/tingling), evaluated on a scale of zero to 10 , zero being no symptoms and 10 as bad as you can imagine. The component score is obtained by taking the average of 13 items. The total proportion score can be obtained when the patient marks at least seven of the 13 items, using the formula: (sum of items answered) $X 13 /$ number of items answered ${ }^{(7)}$.

The component 2, symptoms that interfere with life, has six items (general activity, mood, work, relationships, walking and enjoyment of life) also assessed on a numerical rating scale of zero to 10 , zero being no interference and 10 interfered completely. The mean of the interference items can be used to represent the distress of general symptoms. This mean can be used if more than $50 \%$ (four out of six items) are answered: (sum of answered items) $\times 6 /$ number of answered items ${ }^{(7)}$.

In order to assess the instrument dimensionality, was done an exploratory factor analysis of data by the method of principal components. The factorability of data was evaluated by the index of Kaiser-Meyer-Olkin (KMO), which indicates the proportion of data variance that are common to all variables. The following criteria were adopted to evaluate this test: 1.0 to 0.9 very good; 0.9 to 0.8 good; 0.8 to 0.7 regular; 0.7 to 0.6 reasonable; 0.6 to 0.5 weak; $<0.5$ unacceptable ${ }^{(17)}$. Subsequently was used the technique of Varimax axis rotation.

In order to ensure that each item represented the underlying factor construct, a minimum charge factor of 0.35 was set to accept the item ${ }^{(18)}$. The commonalities for each item were also calculated. They are defined as the portion of item variance explained by the factors retained in the analysis. Values greater than or equal to 0.40 are considered satisfactory ${ }^{(19)}$. The scale accuracy was calculated by means of the Cronbach's alpha coefficient.

The study project was authorized by the researched institution, approved by the Research Ethics Committee (CEP) of the Universidade Federal de São Paulo (UNIFESP) under number 47215 of June 29 2012, and complied with the desired ethical standards.

\section{RESULTS}

The studied population to validate the instrument for use in Portuguese was composed of 268 patients undergoing cancer treatment. Among these, 172 (64.2\%) were women with a mean age of $61.5 \pm 14.9$ years. The level of education had the following variation: 13 (4.9\%) uneducated, $144(53.7 \%)$ with incomplete primary education, 27 (10.1\%) completed primary education, 13 (4.9\%) with incomplete secondary education, 40 (14.9\%) completed secondary education, nine (3.4\%) with incomplete higher education, 15 (5.6\%) with complete higher education, seven $(2.6 \%)$ with complete post-graduate education.

A percentage of $28.4 \%$ of respondents were being treated for secondary tumor, and $51.8 \%$ were in stages III/ IV. Regarding the treatment they had already done or were undergoing, $77.6 \%$ were surgical, $48.1 \%$ were radiotherapy, $70.5 \%$ adjuvant chemotherapy, and $33.2 \%$ neoadjuvant chemotherapy. In relation to the tumor location, 117 were breast cancer (43.7\%), 39 prostate (14.6\%), 20 were colon $(7.5 \%), 13$ head and neck (4.9\%), nine were skin cancer (3.35\%), eight anus (3.0\%), eight lung (3.0\%), seven were chronic myeloid leukemia (2.6\%), four bladder (1.5\%), four esophagus $(1.5 \%)$, six cervix $(2.2 \%)$, four ovarian $(1.5 \%)$, three endometrial (1.1\%), three were testicle cancer (1.1\%), three pancreas (1.1\%) and eight in other sites (3.5\%).

The results of the KMO test showed the data adequacy for factor ana'1lysis (0.792) that explained $56.6 \%$ of variance. Considering the 0.35 cutoff as the minimum load for including the item in the factor, were obtained four factors (Table 1). The factor I gathered the items: sleep problems, distress (upset), difficulty in remembering things and sadness, with an eigenvalue of 3.684 and explaining $16.5 \%$ of the total variance. The factor II was comprised of three items, namely: dizziness, nausea, lack of appetite and vomiting, with an eigenvalue of 1.41 , explaining $31.4 \%$ of the total variance. The factor III was comprised of three items, namely: drowsiness, dry mouth, and numbness/tingling, with an eigenvalue of 1.21 , explaining $44 \%$ of the total variance. The factor IV was composed of the following three items: pain, fatigue and shortness of breath, with an eigenvalue of 1.06 , explaining $56.65 \%$ of the total variance.

The reliability of the MDASI general symptoms was measured by Cronbach's alpha that estimated 0.784 . The specific alpha by factor ranged from 0.662 to 0.697 . The exclusion of any item did not substantially alter the result.

Table 1 - Analysis of the principal components of MDASI symptoms, varimax rotation and Cronbach's alpha - Ijuí, RS, Brazil, 2012

\begin{tabular}{llccccc}
\hline \multirow{2}{*}{ What is the intensity of your symptoms? } & \multicolumn{3}{c}{ Main Components } \\
\cline { 2 - 6 } & Factor I & Factor II & Factor III & Factor IV & $\mathbf{h}^{\mathbf{2} *}$ \\
\hline 1. Pain & 0.251 & 0.010 & 0.249 & $\mathbf{0 . 6 1 3}$ & 0.501 \\
2. Fatigue & 0.166 & 0.131 & 0.156 & $\mathbf{0 . 6 8 0}$ & 0.532 \\
3. Dizziness and nausea & 0.139 & $\mathbf{0 . 7 6 6}$ & 0.060 & 0.239 & 0.666 \\
4. Sleep problems & $\mathbf{0 . 5 5 2}$ & 0.127 & 0.269 & 0.205 & 0.435 \\
5. Distress (upset) & $\mathbf{0 . 8 2 2}$ & 0.115 & 0.028 & 0.126 & 0.706 \\
\hline
\end{tabular}

Continue... 


\begin{tabular}{lccccc}
\hline \multirow{2}{*}{ What is the intensity of your symptoms? } & \multicolumn{3}{c}{ Main Components } \\
\cline { 2 - 6 } & Factor I & Factor II & Factor III & Factor IV & \multicolumn{1}{c}{$\mathbf{h}^{2 *}$} \\
\hline 6. Shortness of breath & 0.005 & 0.100 & -0.024 & $\mathbf{0 . 7 8 5}$ & 0.627 \\
7. Difficulty in remembering things & $\mathbf{0 . 5 1 2}$ & -0.001 & 0.245 & 0.076 & 0.328 \\
8. Lack of appetite & 0.123 & $\mathbf{0 . 7 1 2}$ & 0.164 & 0.071 & 0.554 \\
9. Drowsiness & 0.117 & 0.268 & $\mathbf{0 . 6 4 2}$ & 0.073 & 0.503 \\
10. Dry mouth & 0.053 & 0.161 & $\mathbf{0 . 6 9 6}$ & 0.229 & 0.566 \\
11. Sadness & $\mathbf{0 . 8 3 3}$ & 0.215 & 0.035 & 0.064 & 0.745 \\
12. Vomiting & 0.086 & $\mathbf{0 . 7 9 5}$ & 0.057 & -0.014 & 0.642 \\
13. Numbness and tingling & 0.243 & -0.084 & $\mathbf{0 . 7 0 2}$ & 0.032 & 0.560 \\
\hline Cronbach's alpha & 0.697 & 0.671 & 0.655 & 0.662 & $\mathbf{0 . 7 8 4} * *$ \\
\hline
\end{tabular}

Note: Rotation method: Varimax with Kaiser normalization.

${ }^{*}$ h2: Commonality. ${ }^{* *}$ Overall.

The KMO (0.780) was obtained from the principal component analysis, showing the existence of a single factor that explained $49.9 \%$ of the variance. The factor analysis with oblique rotation showed that the factor found is composed of six items (Table 2 ).

Table 2 - Analysis of the principal components of the MDASI Interferences - Ijuí, RS, Brazil, 2012

\begin{tabular}{lcc}
\hline $\begin{array}{l}\text { MDASI } \\
\text { Interferences }\end{array}$ & Factor $\mathbf{1}$ & h2* \\
\hline Activity in general & 0.785 & 0.615 \\
Mood & 0.740 & 0.547 \\
Work & 0.731 & 0.534 \\
Relationships & 0.691 & 0.477 \\
Walking & 0.543 & 0.294 \\
Enjoyment of life & 0.726 & 0.528 \\
\hline Cronbach's alpha & --- & $0.794^{* *}$ \\
\hline Note: Extraction method - Analysis of the principal component. ${ }^{*} \mathrm{~h} 2:$
\end{tabular}

The reliability of the MDASI interferences of symptoms in the last 24 hours was 0.794 . The exclusion of any item did not substantially alter the result. The Cronbach's alpha evaluation of the overall MDASI (symptoms and interference) was 0.857 .

When assessing to which extent the symptoms were interfering in the lives of respondents, the highest prevalence for interference were the following items: activity in general (59.7\%), work (54.9\%) and walking (49.3). The averages were (3.97 \pm 3.77$),(3.77 \pm 3.87)$ and

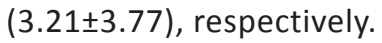

The median of the factors that interfere in the lives of patients showed that for $50 \%$ of respondents, interference was grade 4 in relation to daily activities and grade 3 for interference at work. These data can be analyzed in Table 3.

Tabela 3 - Descriptive statistics of the symptoms reported in the last 24 hours and their interference in the daily life of patients undergoing cancer treatment - Ijuí, RS, Brazil, 2012

\begin{tabular}{|c|c|c|c|c|c|c|c|}
\hline \multirow{2}{*}{ MDASI* } & \multicolumn{2}{|c|}{ Prevalence } & \multirow{2}{*}{ Mean } & \multirow{2}{*}{ SD } & \multicolumn{3}{|c|}{ Percentile } \\
\hline & $\mathrm{N}$ & $\%$ & & & 25 & 50 & 75 \\
\hline \multicolumn{8}{|l|}{ Symptoms } \\
\hline Pain & 122 & 45.5 & 2.51 & 3.15 & 0 & 0 & 5 \\
\hline Fatigue & 169 & 63.1 & 3.52 & 3.26 & 0 & 4 & 6 \\
\hline Feeling sick (nausea) & 54 & 20.1 & 1.20 & 2.65 & 0 & 0 & 0 \\
\hline Sleep problems & 99 & 36.9 & 2.40 & 3.43 & 0 & 0 & 5 \\
\hline Distress (upset) & 146 & 54.7 & 3.36 & 3.64 & 0 & 2 & 6 \\
\hline Shortness of breath & 50 & 18.7 & 0.99 & 2.37 & 0 & 0 & 0 \\
\hline Difficulty in remembering things & 150 & 56.2 & 3.11 & 3.37 & $\mathbf{0}$ & 2 & 5 \\
\hline Lack of appetite & 87 & 32.5 & 1.74 & 2.91 & 0 & 0 & 3 \\
\hline Drowsiness & 126 & 47.2 & 2.63 & 3.21 & 0 & 0 & 5 \\
\hline Dry mouth & 146 & 54.9 & 3.34 & 3.63 & 0 & 2 & 7 \\
\hline Sadness & 120 & 45.1 & 2.71 & 3.47 & 0 & 0 & 5 \\
\hline Vomiting & 18 & 6.7 & 0.45 & 1.82 & 0 & 0 & 0 \\
\hline Numbness and tingling & 109 & 40.7 & 2.51 & 3.52 & 0 & 0 & 5 \\
\hline \multicolumn{8}{|l|}{ Interference } \\
\hline Activity in general & 160 & 59.7 & 3.97 & 3.77 & 0 & 4 & 8 \\
\hline Mood & 116 & 43.3 & 2.60 & 3.43 & 0 & 0 & 5 \\
\hline$\overline{\text { Work }}$ & 147 & 55.1 & 3.77 & 3.87 & 0 & 3 & 8 \\
\hline Relationships & 59 & 22.1 & 1.48 & 3.06 & 0 & 0 & 0 \\
\hline Walking & 132 & 49.4 & 3.21 & 3.77 & 0 & 0 & 7 \\
\hline Enjoyment of life & 86 & 32.1 & 2.07 & 3.41 & 0 & 0 & 5 \\
\hline
\end{tabular}

*M.D. Anderson symptoms inventory 
With regard to symptoms, $50 \%$ of respondents rated the fatigue as intensity 4 (in a score of 0-10); being distressed (upset) and the feeling of dry mouth as grade 2 of intensity. The symptoms with highest prevalence were fatigue (63.1\%), difficulty in remembering things (56.2\%), distress (upset) (54.5\%) and dry mouth (54.5\%). These symptoms also had the highest mean values: $3.52( \pm 3.26)$, $3.11( \pm 3.37), 3.36( \pm 3.64)$ and $3.34( \pm 3.63)$, respectively.

\section{DICUSSION}

The identification of multiple symptoms is of essential importance for patients, hence, health professionals should make use of instruments that measure such symptoms as the MDASI, which can be applied to homogeneous or heterogeneous samples ${ }^{(20)}$. The symptoms are prevalent and severe in patients with cancer. Any clinical study to evaluate the impact of treatment should consider the assessment of symptoms, mainly in patients at advanced stages of disease ${ }^{(21)}$.

The analyzes carried out to test the reliability of the instrument were satisfactory (alpha $\geq 0.70$ ) in its two components, the MDASI symptoms and interferences, confirming the instrument reliability. The exclusion of any item did not substantially alter the result, tested by the Cronbach's alpha.

The findings regarding the psychometric properties of the MDASI are consistent with the findings of previous studies published with samples from other countries and other cultures. In the validation of the MDASI for the Chinese language, the researchers obtained the Cronbach's alpha results of $0.86,0.84$ and 0.90 for the instrument in general, symptoms and interferences, respectively ${ }^{(10)}$. Similarly, in this study, the exclusion of any item did not result in significant changes.

The initial assumption was that the MDASI Symptoms and the MDASI Interference were formed by a single factor each. However, the factor analysis of the MDASI Symptoms produced four factors: factor I, covering the symptoms of sadness, distress (upset), sleep problems and difficulty in remembering things; factor II, with the signs and symptoms of vomiting, dizziness/nausea and lack of appetite; factor III, with symptoms of numbness/tingling, dry mouth, drowsiness; and factor IV, with shortness of breath, fatigue and pain.

The original study in English identified two factors: one comprising the general symptoms (fatigue, pain, dyspnea, difficulty in remembering things, distress (upset), numbness/tingling, dry mouth, sadness, insomnia and drowsiness), with Cronbach's alpha $=0.85$; and another factor was related to gastrointestinal symptoms (nausea and vomiting), with Cronbach's alpha $=0.82^{(7)}$.

Comparing the findings of the current study with the validations of MDSI-core of Japanese ${ }^{(8)}$ and American ${ }^{(7)}$ studies, it was found that emotional symptoms such as distress (upset) and sadness are rarely addressed in practice during consultations, although strongly present and associated with physical symptoms, such as fatigue, pain, drowsiness, dizziness, among others. The convergence of findings indicates that the occurrence of emotional symptoms is quite independent from the cultural characteristics of citizenship of patients. Such findings should expand the clinical evaluation that invariably favors the physical symptoms and does not associate their severity with the emotional responses that may be influencing in their genesis or aggravation.

In the present study, the analysis of the principal components of the MDASI Interferences resulted exclusively in only one factor, unlike the Greek study ${ }^{(9)}$ with three factors, and the American ${ }^{(7)}$ with two factors. The features that suffered greater interference were the activity in general, work and locomotion, aggravated by the symptoms of fatigue, difficulty in remembering things, distress (upset) and dry mouth. The symptoms of greater interference in the assessed items were distress (upset) in the Greek study ${ }^{(9)}$, and fatigue and sadness in the Japanese study ${ }^{(8)}$.

The clinical oncology treatments are known to produce plurality of symptoms including fatigue, pain, disturbed sleep, distress (upset), and loss of appetite, which may vary over treatment. Such symptoms can be severe and extremely debilitating(22), particularly when associated with advanced stages of disease, as in the case of the studied population. Thus, the higher the impairment of the clinical functional capacity, the lower the patient's ability to perform activities of life ${ }^{(14)}$.

In the national study, the entire sample had already undergone a type of treatment, and for a third, the current situation was disease relapse. This allows analyzing that the respondents amounted favorable clinical conditions to obtain conclusive data on the evaluation of their signs and symptoms. However, they have also denoted significant impairment of their general functions, including mobility and work capacity.

\section{CONCLUSION}

The Brazilian version of the MD Anderson - core proved to be valid and reliable for the Brazilian reality in the context of the region in which it was assessed.

The results regarding the validity and reliability of the MDASI give additional support to the applicability of the instrument in research in oncology. Future studies may be carried out to assess multiple symptoms and interference in life over the last 24 hours, offering new perspectives to discuss this subject, aiming at improving the management of symptoms in these patients. It is recommended to validate the instrument with patients from other Brazilian regions.

Study limitations: The findings are relevant to a particular population group, with its social, cultural, economic conformation, and within the own SUS care, which has the same features and potentialities in every region of the country. 


\section{REFERENCES}

1. Ferreira DB, Farago PM, Reis PED, Funghetto SS. Nossa vida após o câncer de mama: percepções e repercussões sob o olhar do casal. Rev Bras Enferm. 2011;64(3): 536-44.

2. Brateibach V, De Domenico ELB, Berlezi EM, Loro MM, Rosanelli CLSP, Gomes JS, et al. Sintomas de pacientes oncológicos em tratamento. Ciênc Saúde. 2013;6(2):102-9.

3. Kolankiewicz ACB, Souza MM, Magnago TSBS, De Domenico EBL. Apoio social percebido por pacientes oncológicos e sua relação com as características sociodemográficas. Rev Gaúcha Enferm. 2014;35(1):31-8.

4. Santana JJRA, Zanin CR, Maniglia JV. Pacientes com câncer: enfrentamento, rede social e apoio social. Paidéia. 2008;18(40):371-84.

5. Ferreira KASL, William Junior WN, Mendonza TR, Kimura $M$, Kowalski LP, Rosenthal DI, et al. Tradução para a língua portuguesa do M.D. Anderson Symptom Inventory headandneck module (MDASI-H\&N). Rev Bras Cir Cabeça Pescoço. 2008; 37(2):109-13.

6. Pan $\mathrm{HH}$, Lin $\mathrm{KC}$, Ho ST, Liang $\mathrm{CY}$, Lee $\mathrm{SC}$, Wang $\mathrm{KY}$. Factors related to daily life interference in lung cancer patients: A cross-sectional regression tree study. Eur J Oncol Nurs. 2012;16(4):345-52.

7. Cleeland CS, Mendoza TR, Wang XS, Chou C, Harle M, Morrissey $M$, et al. Assessing symptom distress in cancer: the $M$. D. Anderson Symptom Inventory. Cancer. 2000;89(7):1634-46.

8. Okuyama T, Wang XS, Akechi T, Mendoza TR, Hosaka T, Cleeland CS, et al. Japanese version of the M. D. Anderson Symptom Inventory: a validation study. J Pain Symptom Manage. 2003;26(6):1093-104.

9. Mystakidou K, Cleeland C, Tsilika E, Katsouda E, Primikiri A, Parpa E, et al. Greek M. D. Anderson Symptom Inventory: validation and utility in a cancer patient population. Oncology. 2004;67(3-4):203-10.

10. Wang XS, Wang Y, Guo H, Mendoza TR, Hao XS, Cleeland CS. Chinese version of the M. D. Anderson Symptom Inventory: validation and application of symptom measurement in cancer patients. Cancer. 2004;101(8):1890-901.

11. Ivanova MO, Ionova TI, Kalyadina SA, Uspenskaya OS, Kishtovich AV, Guo Het al. Cancer-related symptom assessment in Russia: validation and utility of the Russian M. D. Anderson Symptom Inventory. J Pain Symptom Manage. 2005;30(5):443-53.
12. Yun YH, Mendoza TR, Kang IO, You CH, Roh JW, Lee CG, et al. Validation study of the Korean version of the M.D. Anderson Symptom Inventory. J Pain Symptom Manage. 2006;31(4):345-52.

13. Lin CC, Chang AP, Cleeland CS, Mendoza TR, Wang XS. Taiwanese version of the $M$. D. Anderson Symptom Inventory: symptom assessment in cancer patients. J Pain Symptom Manage. 2007;33(2):180-88.

14. Wang XS, Laudico AV, Guo H, Mendoza TR, Matsuda ML, Yosuico VD, et al. Filipino version of the M. D. Anderson Symptom Inventory (MDASI-F): Validation and multisymptom measurement in cancer patients. J Pain Symptom Manage. 2006;31(6):542-52.

15. Nejmi M, Wang XS, Mendoza TR, Gning I, Cleeland CS. Validation and application of the Arabic version of the M. D. Anderson Symptom Inventory in Moroccan patients with cancer. J Pain Symptom Manage. 2010;40(1):75-86.

16. Guirimand F, Buyck JF, Lauwers-Allot E, Revnik J, Kerguen $\mathrm{T}$, Aegerter $\mathrm{P}$, et al. Cancer-related symptom assessment in France: validation of the French M. D. Anderson Symptom Inventory. J Pain Symptom Manage. 2010;39(4):721-33.

17. Tabachnick B, Fidell L. Using multivariate statistics. New York: Harper Collins; 2001.

18. Hair JF Jr, Black WC, Babin BB, Anderson RE, Tatham RL. Análise multivariada de dados. 5a ed. Porto Alegre: Bookman; 2005.

19. Norris M, Lecavalier L. Evaluating the use of exploratory factor analysis in developmental disability psychological research. J Autism Dev Disord. 2010;40(1):8-20.

20. Miaskowski C, Aouizerat BE, Dodd M, Cooper B. Conceptual issues in symptom clusters research and their implications for quality-of-life assessment in patients with cancer. J Natl Cancer Inst Monogr. 2007;(37):37-46.

21. Reilly CM, Bruner DW, Mitchell SA, Minasian LM, Basch E, Dueck AC, et al. A literature synthesis of symptom prevalence and severity in persons receiving active cancer treatment. Support Care Cancer. 2013;21(6):1525-50.

22. Shi Q, Trask PC, Wang XS, Mendoza TR, Apraku WA, Malekifar $M$, et al. Does recall period have an effect on cancer patients' ratings of the severity of multiple symptoms? J Pain Symptom Manage. 2010;40(2):191-9. 